\title{
Crystal structure of the inclusion complex of cholesterol in $\beta$-cyclodextrin and molecular dynamics studies
}

\author{
Elias Christoforides, Andreas Papaioannou and Kostas Bethanis*
}

\author{
Full Research Paper \\ Address: \\ Department of Biotechnology, Agricultural University of Athens, 75 \\ lera Odos, Athens 11855, Greece \\ Email: \\ Kostas Bethanis ${ }^{*}$ - kbeth@aua.gr \\ * Corresponding author \\ Keywords: \\ beta-cyclodextrin; cholesterol; crystal structure; molecular dynamics
}

Beilstein J. Org. Chem. 2018, 14, 838-848.

doi:10.3762/bjoc. 14.69

Received: 28 November 2017

Accepted: 22 March 2018

Published: 11 April 2018

Associate Editor: H. Ritter
(C) 2018 Christoforides et al.; licensee Beilstein-Institut.

License and terms: see end of document.

\begin{abstract}
The role of beta-cyclodextrin $(\beta-C D)$ in cholesterol removal primarily from mammalian cells and secondly from dairy products has been studied thoroughly in recent years. Although the physicochemical characterization of the inclusion compound of cholesterol in $\beta$-CD has been achieved by various methods, no crystal structure has been determined so far. We report here the crystal structure of the inclusion compound of cholesterol in $\beta-\mathrm{CD}$. The inclusion complex crystallizes in the triclinic space group $P 1$ forming head-tohead dimers which are stacked along the $c$-axis. One well-defined cholesterol molecule 'axially' encapsulated inside the $\beta$-CD dimer and 22 water molecules that stabilize the complexes in the crystalline state comprise the asymmetric unit of the structure. The dimers are arranged in an intermediate (IM) channel packing mode in the crystal. Moreover, MD simulations, at 300 and $340 \mathrm{~K}$, based on the crystallographically determined coordinates of the complex show that the formed cholesterol $/ \beta$-CD inclusion compound remains very stable in aqueous solution at both temperatures.
\end{abstract}

\section{Introduction}

Cholesterol ((3ß)-cholest-5-en-3-ol, CHL, Figure 1a) is a polycyclic steroid that is synthesized in mammalian cells and has a significant role in biology as an essential structural component of the cell walls and as precursor for the biosynthesis of several substances such as vitamin D, bile acids and steroid hormones. However, the consumption of food rich in cholesterol like meat, eggs and dairy products has been associated with many diseases such as atherosclerosis, hypertension, coronary heart disease, heart stroke and cerebral infarction [1]. Moreover, the abnormal accumulation of cholesterol in endolysosomes emerging from inherited lysosomal storage disorders known as Niemann-Pick type C disease (NPC) leads to various clinical symptoms, such as progressive neurodegeneration and hepatosplenomegaly, often resulting in fatality at an early age [2]. As the cholesterol exchange between tissues at the whole body level and fundamental insights into the physiology of cholesterol trafficking are 
already known, the development of drug carriers and cell cholesterol removal agents for controlling cholesterol-related disorders [3] are of special interest.

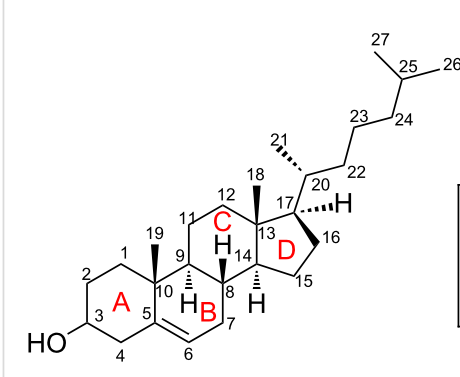

a

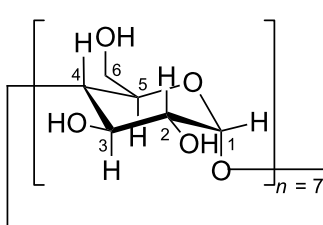

b
Figure 1: Schematic representation of (a) the cholesterol molecule; (b) the $\beta$-cyclodextrin molecule.

$\beta$-Cyclodextrin ( $\beta$-CD, Figure $1 b)$ is a cyclic polysaccharide consisting of seven $\alpha$-(1->4)-linked $\alpha$-D-glucopyranose units and is well known for its ability to form inclusion complexes by entrapping a wide range of guest molecules into its internal hydrophobic cavity. It is non-toxic, non-irritating, edible, chemically stable, easy separable and widely used in pharmaceutical, food and chemical industry [4]. Two major cyclodextrin applications dictate a meticulous study of their inclusion complexes with the cholesterol molecule. $\beta-\mathrm{CD}$ and its modified derivatives (2,6-di- $O$-methyl- $\beta$-CD or DM- $\beta-\mathrm{CD}$, randomly methylated $\beta$-CD or RAMEB and 2-hydroxypropyl- $\beta$-CD or HP- $\beta$ $\mathrm{CD})$ comprise a class of pharmacological agents commonly used to remove membrane cholesterol from cells [5-8]. Cholesterol depletion using CDs is advantageous over the use of binding agents like digitonin, filipin and saponin which are not compatible with live cells. Recently, the use of cyclodextrin as a valuable therapeutic agent for treatment of NPC disease, for which no effective treatment is currently available, has been investigated. It has been shown that administration of HP- $\beta-C D$ has significantly reduced lysosomal cholesterol accumulation albeit the need for high doses is likely to be detrimental and might cause cell death [9-11]. Sulfobutyl ether- $\beta-C D$ and sulfobutyl ether- $\gamma$-CD showed efficacy with increased safety in NPC animal models [12]. Moreover, superstructures of cyclodextrins like mono-lactose-appended $\beta$-CD [13] and biocleavable pluronic/ $\beta$-CD-based polyrotaxanes $[14]$ as well as PEGlipid micelles (DSPE-PEG) in combination with HP- $\beta$-CD [15] have shown enhanced therapeutic effects and exhibit a reduced toxicity. In food industry $\beta$-CD has been used in many applications such as flavor protection and flavor delivery, controlled release of desired constituents and removal and masking of undesirable components [16]. But the most prevalent use of CD in this field is the removal of cholesterol from animal products like milk [17], butter [18], cheese [19] and eggs [20] which contains more than $90 \%$ less cholesterol when treated with $\beta$-CD. As consumers are becoming more and more concerned about their eating habits, food companies have developed many techniques to reduce cholesterol, as extraction with organic solvents, supercritical carbon dioxide extraction or cholesterol degradation by cholesterol oxidases. But these methods are not selective as other components are also removed and they require expensive equipment and high operational cost [21].

In the past, many studies have been published on the characterization of the cholesterol/ $\beta-C D$ inclusion complex [22], its binding affinity [23-25], the inclusion mode of the complex [26] and its dynamic behavior through MD simulations [27-29] but its crystal structure is absent. In this work, the structure of CHL/ $\beta$-CD is determined by X-ray crystallography and its geometrical features are examined thoroughly. In order to examine the stability of the crystallographically determined model excluding the crystal contacts observed in the crystalline state, MD simulations of the inclusion complex in aqueous environment were performed. The starting set of coordinates was based on the asymmetric unit of the determined structure and the dynamic behavior of the inclusion complex was monitored at two different temperatures ( 300 and $340 \mathrm{~K}$ ) to gain some insight on the evolution of the host-guest interactions and to estimate the host-guest binding affinity in aqueous solution.

An understanding of the structural details of cholesterol inclusion in CDs may be useful in the engineering of modified guest-host preparations with optimized pharmacological properties and shape future therapeutic strategies. Since there are other similar molecules, such as plant sterols that share certain chemical groups, our findings may be relevant for these guests as well.

\section{Results and Discussion Description of the crystal structure}

The complex crystallizes in the $P 1$ space group with lattice parameters quoted in Table 1. Its asymmetric unit contains two $\beta$-CD host molecules (denoted as host A and host B) arranged co-axially so that the secondary rim (head) of the one faces the secondary rim of the other forming a head-to-head dimer via intermolecular hydrogen bonds between their $\mathrm{O} 3 n-\mathrm{H}$ hydroxy groups. A cholesterol molecule is found fully encapsulated inside the $\beta$-CD dimeric cavity, therefore the host:guest stoichiometry of the inclusion complex is 2:1 (Figure 2a). The unit cell contains also 22 water molecules distributed over 35 sites.

The cholesterol molecule is accommodated 'axially' in the $\beta-\mathrm{CD}$ dimeric cavity. The mean plane of its $\mathrm{ABCD}$ ring system is perpendicular to the mean plane of the glucosidic $\mathrm{O} 4 n$ atoms 
Table 1: Experimental details for the cholesterol/ $\beta-C D$ inclusion compound.

cholesterol/ $\beta-C D$

\begin{tabular}{ll}
\hline crystal data & \\
\hline chemical formula & $\mathrm{C}_{42} \mathrm{H}_{70} \mathrm{O}_{35} \cdot \mathrm{C}_{42} \mathrm{H}_{70} \mathrm{O}_{35} \cdot \mathrm{C}_{27} \mathrm{H}_{46} \mathrm{O} \cdot 22\left(\mathrm{H}_{2} \mathrm{O}\right)$ \\
$M_{\mathrm{r}}$ & 1504.94 \\
crystal system, space group & triclinic, $P 1$ \\
temperature $(\mathrm{K})$ & 100 \\
$a, b, c(\AA)$ & $15.16(3), 15.60(3), 17.84(3)$ \\
$\alpha, \beta, \mathrm{Y}\left({ }^{\circ}\right)$ & $114.02(14), 99.33(13), 102.08(12)$ \\
$V\left(\AA^{3}\right)$ & $3623(12)$ \\
radiation type & $\mathrm{Cu} \mathrm{K \alpha}$ \\
$\mathrm{m}\left(\mathrm{mm}^{-1}\right)$ & 1.06 \\
crystal size $(\mathrm{mm})$ & $0.23 \times 0.12 \times 0.07$
\end{tabular}

data collection

diffractometer absorption correction

$T_{\min }, T_{\max }$

no. of measured,

independent and observed

$[I>2 \mathrm{~s}(I)]$ reflections

$R_{\text {int }}$

$\theta_{\max }\left({ }^{\circ}\right)$

$(\sin \theta / \lambda)_{\max }\left(\AA^{-1}\right)$

refinement

$R\left[F^{2}>2 \mathrm{~s}\left(F^{2}\right)\right], w R\left(F^{2}\right), S$

no. of reflections

no. of parameters

no. of restraints

$\mathrm{H}$-atom treatment

$D \rho_{\max }, D \rho_{\min }\left(\mathrm{e} \AA^{-3}\right)$

absolute structure

absolute structure

parameter

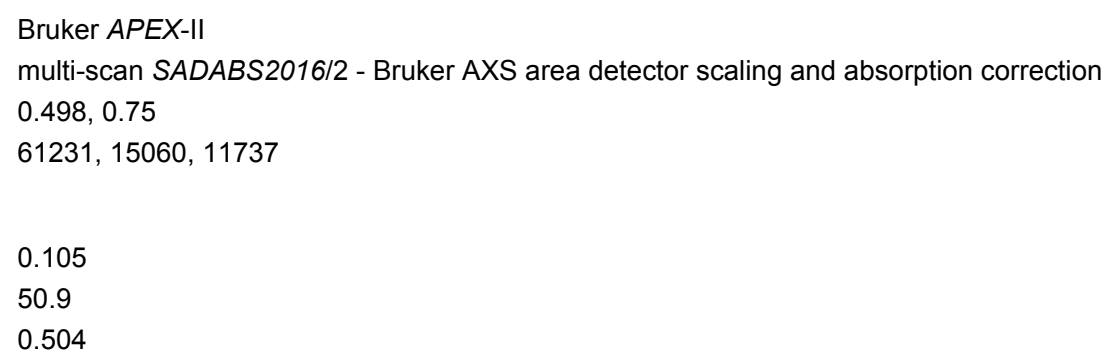

$0.083,0.224,1.03$

15060

1153

82

$\mathrm{H}$-atom parameters constrained

$0.71,-0.43$

Flack $x$ determined using 4403 quotients $[(I+)-(I-)] /[(I+)+(I-)]$ (Parsons, Flack and Wagner, Acta Cryst. B 2013, 69, 249-259).

$0.04(13)$ of the hosts forming an angle of $83.18(16)^{\circ}$ with it. The sterol group of the guest is tightly fitted inside the hydrophobic cavity of the host A whereas its aliphatic 'tail' is located inside the hydrophobic cavity of the other host (host B) and characterized by high atomic displacement parameters in an effort to fill the "free" space inside the host B cavity (Figure 2b). The hydroxy group of cholesterol protrudes from the primary rim of host A (distance between the oxygen atom of the CHL hydroxy group and the mean plane of O4n atoms of host A is 5.329 (12) $\AA$ ), hydrogen bonded with primary hydroxy groups of vicinal $\beta-C D$ dimers $(\mathrm{O} 1 \cdots \mathrm{O} 63 \mathrm{~B}(1+x, y, z)=2.688(4) \AA$, and $\mathrm{O} 1 \cdots \mathrm{O} 66 \mathrm{~B}(x$, $-1+y, z)=2.721(5) \AA$,) aiding the crystal packing and also affecting the inclusion depth of the guest in the crystalline state (Figure 2c). The inclusion complex gains stability from numer- ous van der Waals and $\mathrm{C}-\mathrm{H} \cdots \mathrm{O}$ interactions mainly between the guest and the inner dimeric host cavity. The observed host-guest interactions along with the extended hydrogen bond network between water molecules, hosts and guest are listed analytically in Supporting Information File 1, Table S1.

In particular, the side of $\mathrm{C} 1$ and $\mathrm{C} 2$ atoms of ring $\mathrm{A}$ and the opposite side of $\mathrm{C} 6$ and $\mathrm{C} 7$ atoms of ring $\mathrm{B}$ of $\mathrm{CHL}$ form closed-shell weak $\mathrm{H} \cdots \mathrm{H}$ interactions with the inner hydrogens ( $\mathrm{H} 5$ and $\mathrm{H} 3$ ) of the oppositely located glucopyranoses of host A (G2, G3 and G6, G7, respectively). C2-H2A of ring A and $\mathrm{C} 7-\mathrm{H} 7 \mathrm{~A}$ of ring $\mathrm{B}$ also form $\mathrm{C}-\mathrm{H} \cdots \mathrm{O}$ bonds with the $\mathrm{O} 63 \mathrm{C}$ primary hydroxy group (partially occupied site, sof $=0.4$ ) and the glycosidic O46A atom, respectively. The tight fit of the sterol 


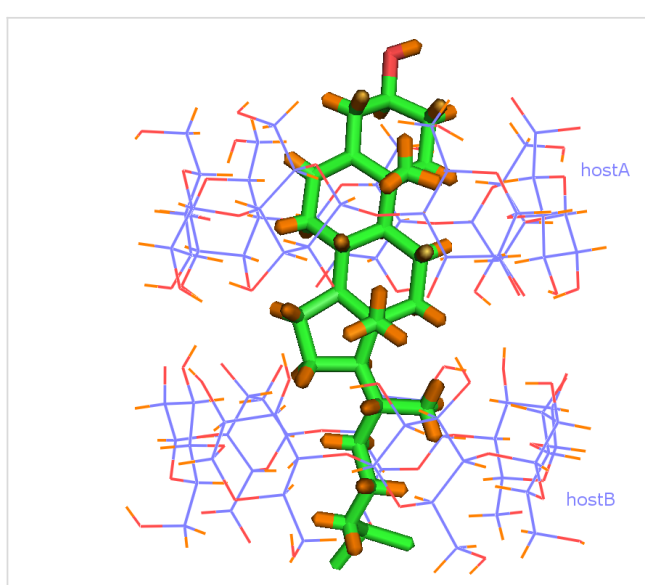

a

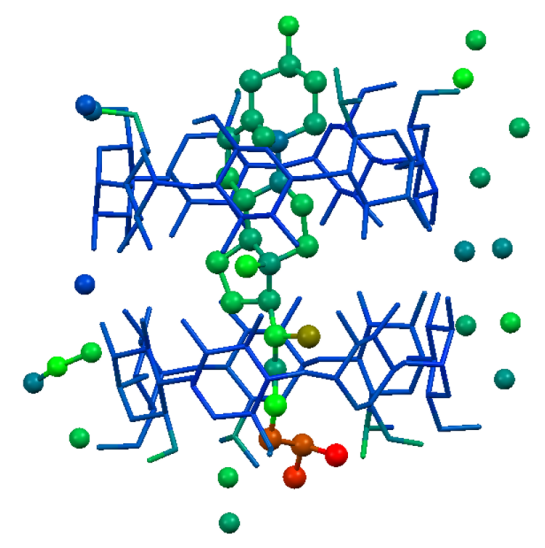

b

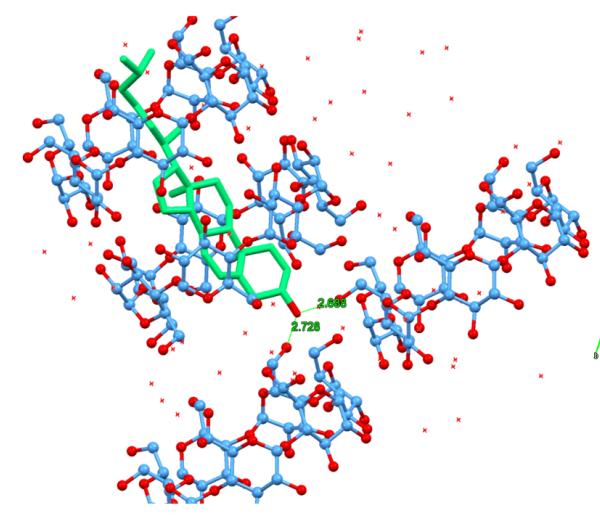

C
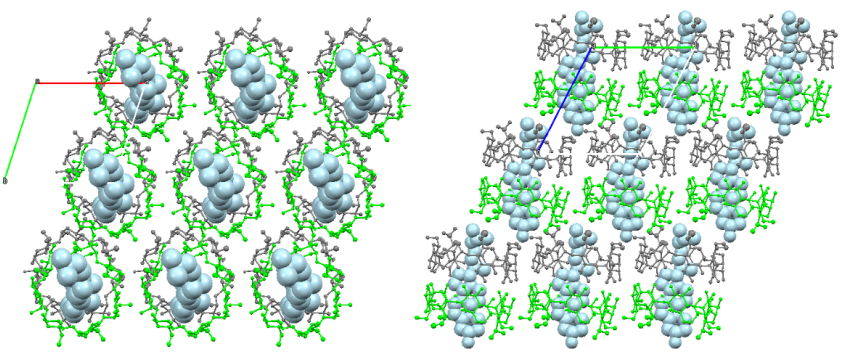

d

Figure 2: (a) Crystal structure of the inclusion compound of cholesterol in $\beta-C D$ dimer. Water molecules are omitted for clarity. (b) The inclusion complex colored by atomic displacement parameters $(U$ 's) using Mercury 3.9. The values of $U$ increase from blue to red colour. (c) The hydroxy group of cholesterol is hydrogen bonded with the hydroxy groups of the primary rim of vicinal $\beta$-CD dimers. (d) Inclusion complexes stack along the crystallographic $c$-axis according to the Intermediate Channel (IM) packing mode. Projection along the c-axis (left) and a-axis (right).

group of the guest in host A hydrophobic cavity, is further enhanced by the $\mathrm{H} \cdots \mathrm{H}$ interactions between the hydrogens of the C19 methyl group, which is perpendicular to the mean plane of the sterol's ring system, and the inner H5 hydrogens of the 3rd and 4th glucopyranose of host A macrocycle. The C18 methyl group of the guest, which has the same orientation with that of $\mathrm{C} 19$, is located at the interface of the $\beta-\mathrm{CD}$ dimer and does not interact with the host molecules. The $\mathrm{C} 21$ cholesterol methyl group being perpendicular to the $\mathrm{C} 18$ and $\mathrm{C} 19$ methyl groups is located in the host B macrocycle cavity and is in close contact with the inner $\mathrm{H} 3$ atom of its 6 th glucopyranose unit (H36C-C36B). The aliphatic tail of the cholesterol molecule protrudes from the primary rim of host $\mathrm{B}$. The hydrogens of its secondary $\mathrm{C} 24$ atom form $\mathrm{C}-\mathrm{H} \cdots \mathrm{O}$ bonds with partially occu- pied water molecule sites located in the interdimeric space. The isopropyl group of the guest projects through the primary hydroxy rim of host $\mathrm{B}$, clearly higher disordered than the sterol group, forming $\mathrm{C}-\mathrm{H} \cdots \mathrm{O}$ bonds with the partially occupied primary hydroxy group O61D ( sof $=0.2$ ) of host B, disordered water molecules located in the dimers' interspace and the primary hydroxy group O66A of host A of the adjacent dimer $(1+x, y,-1+z)$.

Supporting Information File 1, Table S2 lists some parameters defining the conformation of the host molecules. The glucosidic $\mathrm{O} 4 n$ atoms in both host molecules form nearly regular heptagons, which are essentially planar, as indicated by their distances from their approximate centroids $\left(D_{\mathrm{K}}\right)$, the distance 
between adjacent $\mathrm{O} 4 n$ atoms $(D)$ and their deviations $(d)$ from the $\mathrm{O} 4 n$ mean plane. The glycosidic residues have positive tilt angles, indicating that their primary sides incline towards the approximate sevenfold axis of the cavity. The majority of hydroxy groups in both host A and host B have the gauche-gauche conformation pointing outwards the cavity. One disordered hydroxy group in host A and two in host B illustrate both gauche-gauche and gauche-trans conformations pointing inwards and outwards the cavity.

The $\beta$-CD dimers stack along $c$-axis, the angle between their approximate seven-fold axis and $c$-axis being $7.86^{\circ}$, and form layers along the $a-b$ crystal plane. The shift between two successive dimers along the $c$-axis is $5.91 \AA$. This displacement is very close to the average of $6 \AA$ observed in the cases of the dimeric structures crystallizing according to the intermediate channel (IM) packing mode [30]. Therefore, the packing mode of the dimeric structure is characterized as IM (Figure 2d).

According to the classification of dimeric $\beta$-CD inclusion complexes [31], the dimers crystallizing in the $P 1$ space group stack either according to the channel $(\mathrm{CH})$ packing mode, if their cell dimensions are all about $15.5 \AA$, or to the IM packing mode in the case that one of the cell dimensions is more than $17 \AA$ the two others being also about $15.5 \AA$. The Cambridge Structural Database (CSD) [32] search resulted in 26 structures of inclusion compounds in $\beta$-CD with similar cell dimensions. Among them, three entries (ANAXAP [33], UJEFEV [34] and XAMDEX [35]) are found to have a 2:1 host/guest stoichiometry. In all these cases, the shift between two successive dimers along the $c$-axis is $6.017,6.22$ and $6.27 \AA$, respectively. Thus they crystallize also in the IM packing mode.

The first case (ANAXAP), concerns the inclusion of a small molecule model of the $[\mathrm{FeFe}]-\mathrm{H}_{2}$ ase active site, $\left(\mu-\mathrm{SCH}_{2} \mathrm{NH}\left(\mathrm{C}_{6} \mathrm{H}_{4} \mathrm{SO}_{3}{ }^{-}\right) \mathrm{CH}_{2} \mathrm{~S}\right)\left[\mathrm{Fe}^{\mathrm{I}}(\mathrm{CO})_{3}\right]_{2}$, within the cavity of a $1.2 \beta$-CD sodium salt clathrate. 28 water molecules are also found in the asymmetric unit. The incorporation of charged functional groups into the guest molecule of cyclodextrin host/ guest system provides a degree of stability to the inclusion complex. The head-head $\beta$-CD dimers formed by units interacting through hydrogen bonds between their secondary hydroxy groups is further stabilized through ion-dipole interactions with a $\mathrm{Na}^{+}$counterion. This $\mathrm{Na}^{+}$links the two $\beta$-CD's together and also interacts with neighboring units in the extended twodimensional crystalline array.

In the 8-hydroxyquinoline inclusion complex crystal structure (UJEFEV), the asymmetric unit consists of two $\beta$-CDs, one 8 -hydroxyquinoline, two ethanol and thirty water molecules. The hydrophobic cavities of the two $\beta$-CDs forming a head-to- head dimer, contain only ethanol molecules whereas the small, planar 8-hydroxyquinoline molecule is found not being encapsulated but entrapped in a sandwich mode in the interface of the $\beta-\mathrm{CD}$ dimer.

The crystal structure of phenoxodiol $/ \beta-C D$ inclusion complex (XAMDEX) is the only case similar to the CHL/ $\beta-C D$ inclusion complex. Phenoxodiol is an isoflavone analogue that possesses potent anticancer properties. The asymmetric unit of phenoxodiol $/ \beta-C D$ includes one guest molecule encapsulated by two $\beta$-CD molecules, and twenty-six water molecules. All the water molecules surround the external area of the complex bridging the adjacent dimers. The guest phenoxodiol having a length of about $12 \AA$ matches well with the length of the double barrel unit of two $\beta$-CDs $(\approx 14.5 \AA)$ and its terminal hydroxy groups make $\mathrm{O}-\mathrm{H} \cdots \mathrm{O}$ hydrogen bonding contacts with water molecules. However, only one $\mathrm{C}-\mathrm{H} \cdots \mathrm{O}$ bond between the oxygen atom of the guest's benzopyran and an internal hydrogen of the host $(\mathrm{C} 33-\mathrm{H} 33)$ is observed in the crystalline state. Thus, the guest is held in the dimeric $\beta$-CD cavity mainly via bridging molecules of water. Such formation of the inclusion complex is favourable for the facile release of the guest. Indeed, the phenoxodiol molecule is found having an occupancy factor of 0.5 in the $\beta-C D$ dimeric cavity assumed able to be diffused through the crystal channels with the aid of the water network and the structure is characterized as 'ship-in-a-bottle'.

On the other hand, in the case of the CHL/ $\beta$-CD complex, the bulky cholesterol molecule with a length of about $16.5 \AA$ is encapsulated with its hydroxy group and isopropyl terminal groups protruding from the primary hydroxy rim of the hosts and directly bonded with the hosts of the adjacent complex units, its tight fit in the $\beta$-CD dimeric cavity further supported by the above mentioned guest-host interactions. Therefore, cholesterol is always found in the cavity of the $\beta-C D$ dimer, its size and shape prohibiting its diffusion in the crystal.

\section{Molecular dynamics}

The crystallographically determined atomic coordinates of the CHL/ $\beta$-CD complex (host/guest stoichiometry 2:1) (Figure 2a) were subjected to equilibration and subsequent molecular dynamics simulations at both 300 and $340 \mathrm{~K}$ in explicit water solvent for almost $12 \mathrm{~ns}$ with the aim to monitor the dynamic behavior of CHL in $\beta-C D$ in two different temperatures, study the host-guest interactions during the simulation time frame and calculate the host-guest binding affinity in each case. By monitoring the frames during the time interval of the simulations, we observed that the sterol group of the guest cholesterol molecule remains encapsulated inside the hydrophobic $\beta-C D$ dimeric cavity while its aliphatic tail protrudes from the primary rim of the host $\mathrm{B}$ to the solvent in both cases. Figure 3 shows the time 


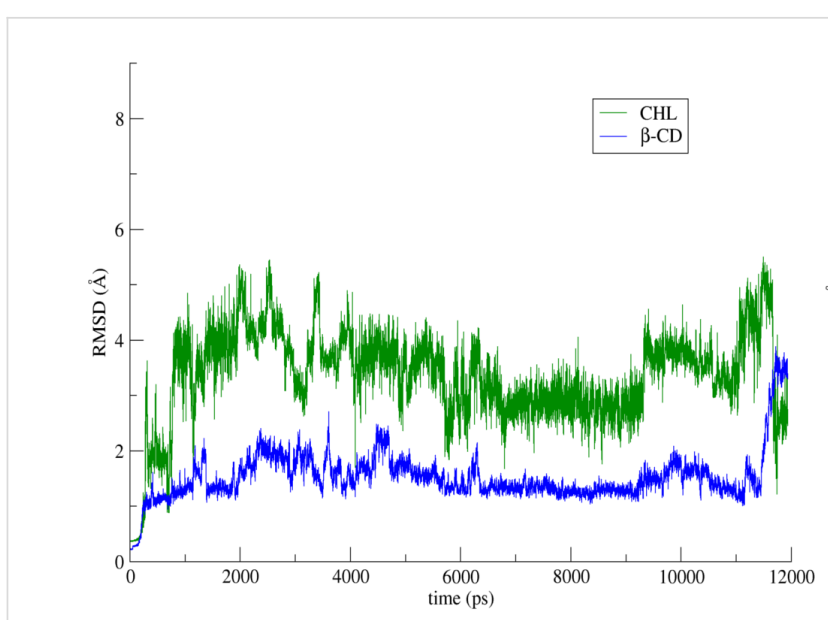

a

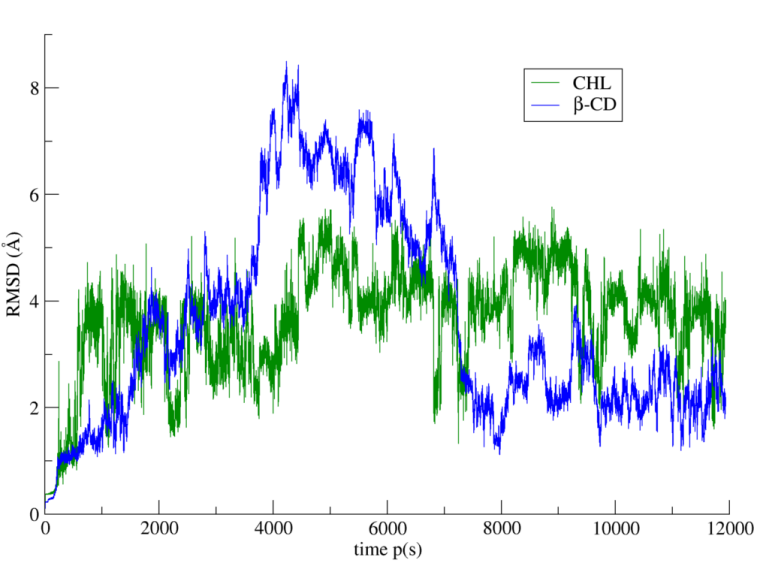

b

Figure 3: RMSD over time for all $\mathrm{CHL}$ (green) and $\beta-\mathrm{CD}$ (blue) atoms (a) at $300 \mathrm{~K}$ and (b) at $340 \mathrm{~K}$.

evolution of the root mean square deviation (RMSD) from the initial structure, calculated for all CHL (green) and $\beta$-CD (blue) atoms in their complex at $300 \mathrm{~K}$ (a) and $340 \mathrm{~K}$ (b). RMSD for $\mathrm{CHL}$ and $\beta-\mathrm{CD}$ are higher in the latter case. Although a significant deformation of the $\beta-\mathrm{CD}$ dimer is observed at $340 \mathrm{~K}$, the dimer is not decomposed during the time frame of this simulation. In both examined cases the CHL molecule shifts from its original position towards the interface of the dimer (Figure $4 \mathrm{a}$ and $b$ ). This shift is favored by the lack of the crystal contacts between the hydroxy group of the guest and vicinal inclusion complexes occurring in the crystalline state (Figure 2c). In Figure 5a, the plot of the distance between the $\mathrm{O} 1$ atom of the guest and the centroid of the $\mathrm{O} 4 n$ atoms of host A during the simulation is given showing this shift and thus a preference of the sterol ring to be accommodated closer to the dimeric interface compared to its initial crystallographically observed site. Moreover, hydrogen-hydrogen interactions that occur initially between ring A atoms (CHL) and H5 (host A), after minimization and $\mathrm{MD}$ run of the system are observed between ring $\mathrm{A}$ atoms (CHL) and H3 (host A) (Figure 4c and d). Although the CHL guest molecule rotates about the seven-fold host molecule axis, the interactions between the hydrogen atoms of its sterol rings $A$ and $B$ with those of the wide rim of $\beta-C D$ (H3) observed also by ${ }^{1} \mathrm{H}$ NMR [26] are retained during the whole 12 ns simulation (Figure $5 b$ ).

The binding affinity of the CHL/ $\beta$-CD complexes in aqueous solution has been previously calculated for different orientations of CHL in $\beta$-CD monomers as well as CHL encapsulation in head-head, head-tail and tail-tail dimers $[24,25,33]$. In this study, the determination by X-ray crystallography of the CHL inclusion in a head-head $\beta-\mathrm{CD}$ dimer conclusively resolves this ambiguity. The binding affinity calculations based on this model give high absolute $\Delta G$ values at both $300 \mathrm{~K}$ and $340 \mathrm{~K}$ temperatures (Table 2) indicating a very stable inclusion complex even at high temperatures. Van der Waals intermolecular forces are the predominant interactions sustaining the complex stability in aqueous solution (Table 2).

\section{Conclusion}

The crystal structure of CHL in $\beta$-CD reveals the formation of a 2:1 host:guest inclusion complex. CHL is found encapsulated axially in a head-to-head $\beta$-CD dimer (host A and host B), tightly bound via numerous van der Waals and $\mathrm{C}-\mathrm{H} \cdots \mathrm{O}$ interactions to the inner dimeric host cavity. The hydroxy group and the isopropyl group of the guest protrude from the primary rim of the host A and host B, respectively, forming crystal contacts with vicinal dimers and water molecules. The $\mathrm{CHL} / \beta-\mathrm{CD}$ inclusion complex crystallizes in the triclinic space group $P 1$ and the dimers are stacked along the $c$-axis according to the IM Channel packing mode.

In previous studies, the proximity between ring $A$ and ring $B$ protons of cholesterol and the secondary rim protons of $\beta-C D$ were indicated by NMR concluding to a probable $2: 1$ host/guest inclusion formation [26]; the formation of 1:1 stoichiometric complexes pointed out by phase solubility [25] or MD studies [29]; favorable inclusion complex formation with $\beta$-CD dimer was shown by molecular modeling, proposing a tail-tail dimer [37] and finally MD calculations concluded that efficient removal of cholesterol from membranes requires the presence of $\beta$-CD dimers [27]. In this work, the crystallographic analysis of $\mathrm{CHL} / \beta-\mathrm{CD}$ complex conclusively clarifies the inclusion mode of CHL in $\beta$-CD head-head dimers. 


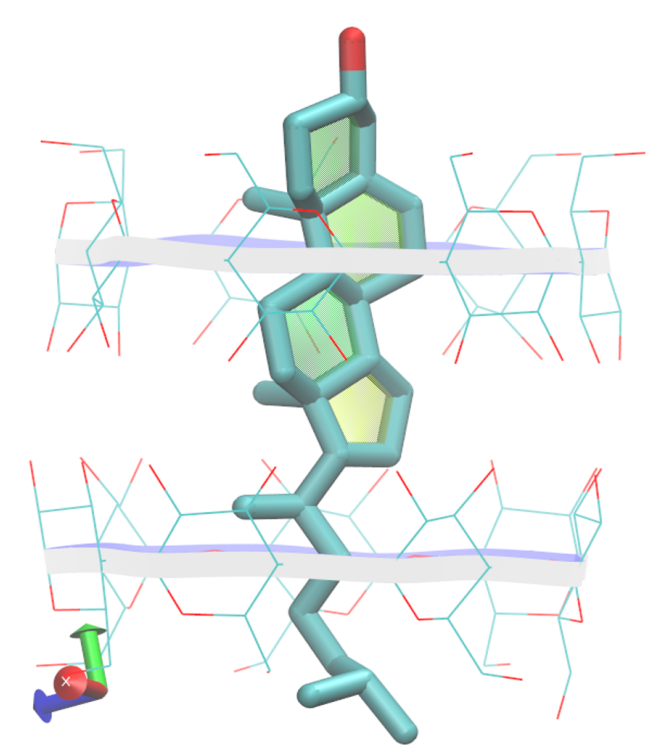

a

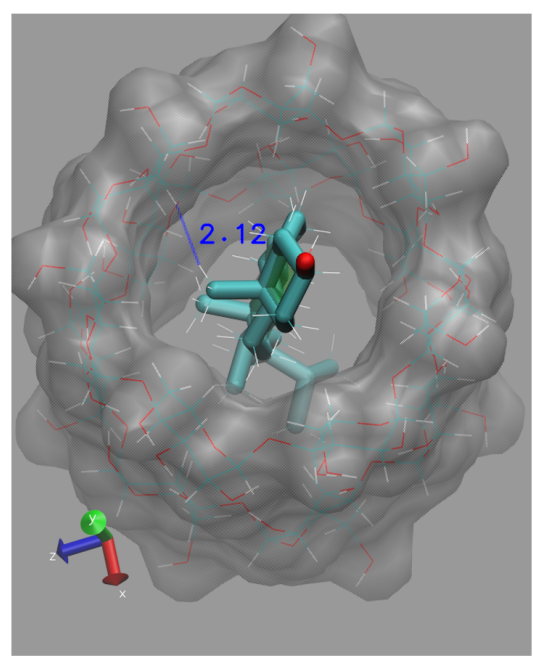

C

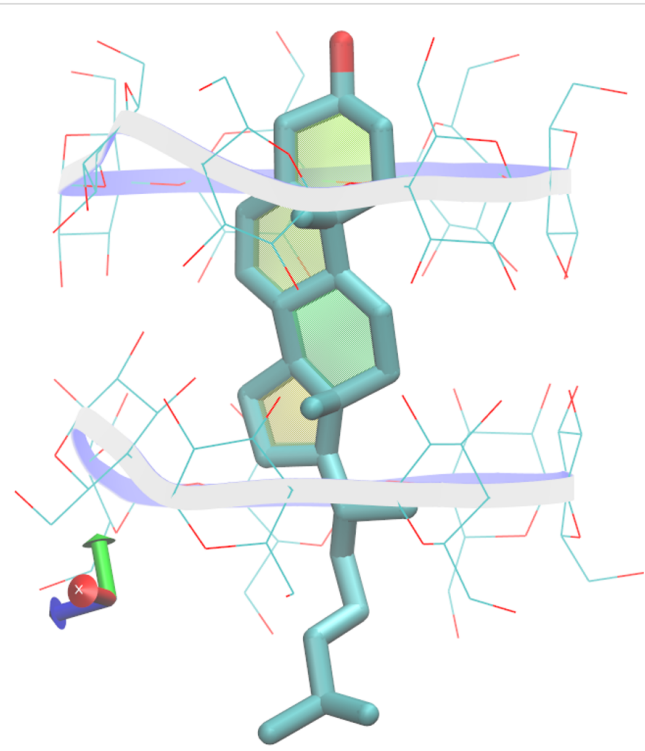

b

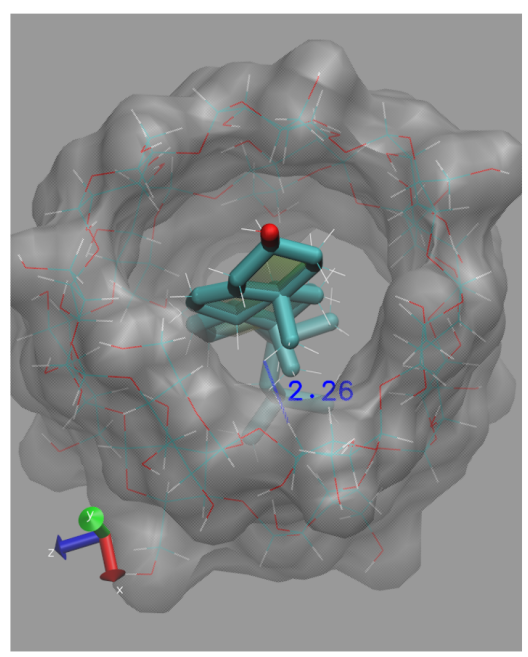

d

Figure 4: Representative snapshots of the CHL/ $\beta-C D$ inclusion complex at $0(a, c)$ and $11 \mathrm{~ns}(\mathrm{~b}, \mathrm{~d})$ in timescale and at $300 \mathrm{~K}$. Water molecules are omitted for clarity. $(a, b)$ Shift of the sterol group of the $\mathrm{CHL}$ molecule towards the $\beta-C D$ dimeric interface. (c, d) $\mathrm{H}-\mathrm{H}$ interactions between $\mathrm{CHL}$ ring $\mathrm{A}$ and $\mathrm{H} 5$ (initially) or $\mathrm{H} 3$ (subsequently) of host $\mathrm{A}$ are retained although $\mathrm{CHL}$ rotates about hosts' seven-fold molecular axes. Image rendering was obtained with the VMD visualization program [36].

The MD simulations that performed based on the crystallographically determined model show that the inclusion complex is very stable in aqueous solution at both 300 and $340 \mathrm{~K}$. In the absence of crystal contacts, van der Waals intermolecular forces are the predominant interactions sustaining the complex stability in aqueous solution. The interactions between the hydrogen atoms of the sterol rings $\mathrm{A}$ and $\mathrm{B}$ of cholesterol and those of the wide rim of $\beta-C D$ which have been also reported previously by ${ }^{1} \mathrm{H}$ NMR studies [26] are retained during the time frame of the MD simulations. Moreover, the high binding affinity values $\Delta G$, estimated at $300 \mathrm{~K}$ and $340 \mathrm{~K}(-19.5$ and
$-19.3 \mathrm{kcal} / \mathrm{mol}$, respectively), indicate that the encapsulation of cholesterol in $\beta$-CD head-head dimer vastly increases the affinity of the CHL/ $\beta-\mathrm{CD}$ inclusion complex compared to models of $1: 1$ host/guest stoichiometry $(-3.3 \mathrm{kcal} / \mathrm{mol}$, [25]) forming a very stable inclusion complex even at high temperatures.

\section{Experimental Chemicals}

Cholesterol $\left(M_{\mathrm{w}}=386.65 \mathrm{~g} / \mathrm{mol}, 99 \%\right.$ purity) and $\beta-\mathrm{CD}$ $\left(M_{\mathrm{W}}=1135,99 \%\right.$ purity) were purchased from Fluka. 


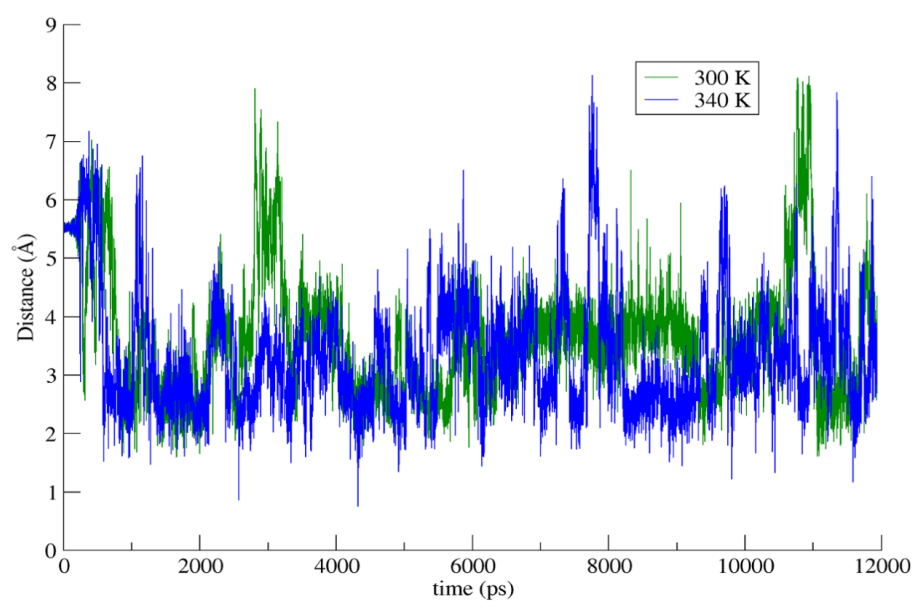

a

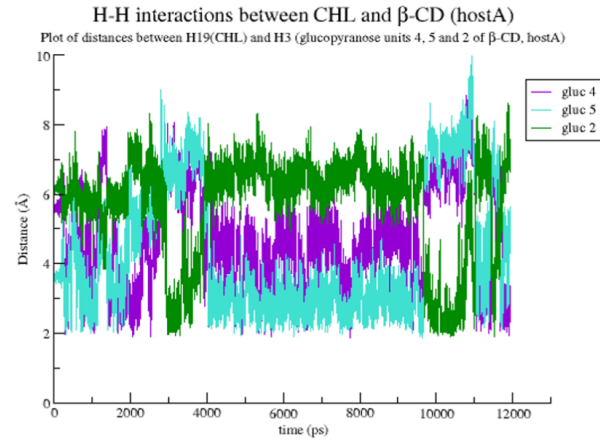

b

Figure 5: (a) Distance between the $\mathrm{O} 1$ atom $(\mathrm{CHL})$ and the centroid $D_{\mathrm{K}}$ of the $\mathrm{O} 4 \mathrm{n}$ atoms of host $\mathrm{A}$ at 300 (green) and $340 \mathrm{~K}$ (blue) and (b) distances between $\mathrm{H} 19$ atom of $\mathrm{CHL}$ (ring $\mathrm{A}$ ) and $\mathrm{H} 3$ atoms of the 4th (purple), 5th (cyan) and 2nd (green) glucopyranose units of host $\mathrm{A}$.

Table 2: Binding free energies (kcal/mole) resulting from MM/GBSA (and normal mode for the entropic term) analysis of the cholesterol/ $\beta$-CD inclusion compound.

energy component

average energy (std. dev.)

\begin{tabular}{|c|c|c|}
\hline & $T=300 \mathrm{~K}$ & $T=340 \mathrm{~K}$ \\
\hline$\Delta E_{\mathrm{vdW}}$ & $-59.4( \pm 2.5)$ & $-58.2( \pm 2.6)$ \\
\hline$\Delta E_{\text {ele }}$ & $-1.9( \pm 2.4)$ & $-2.0( \pm 2.3)$ \\
\hline$\Delta E_{\mathrm{GB}}$ & $24.5( \pm 3.4)$ & $24.6( \pm 3.5)$ \\
\hline$\Delta E_{\text {surf }}$ & $-5.9( \pm 0.2)$ & $-5.9( \pm 0.3)$ \\
\hline$\Delta G_{\text {gas }}$ & $-61.1( \pm 3.4)$ & $-60.1( \pm 3.7)$ \\
\hline$\Delta G_{\text {solv }}$ & $18.6( \pm 3.3)$ & $18.8( \pm 3.3)$ \\
\hline${ }^{*} \Delta G_{\mathrm{GB}}$ & $-42.5( \pm 2.6)$ & $-41.3( \pm 2.8)$ \\
\hline $\mathrm{T} \cdot \Delta S$ & $-23.0( \pm 3.6)$ & $-22.00( \pm 3.9)$ \\
\hline${ }^{* *} \Delta G_{\text {bind }}$ & $-19.5( \pm 4.4)$ & $-19.3( \pm 4.8)$ \\
\hline
\end{tabular}

$\Delta E_{\mathrm{vdW}}=$ van der Waals contribution from MM; $\Delta E_{\text {ele }}=$ electrostatic energy as calculated by the MM force field; $\Delta E_{\mathrm{GB}}=$ the electrostatic contribution to the solvation free energy, calculated by GB model; $\Delta E_{\text {surf }}=$ nonpolar contribution to the solvation free energy, calculated by an empirical model; ${ }^{*} \Delta G_{\mathrm{GB}}=\Delta G_{\text {solv }}+\Delta G_{\text {gas }} ;{ }^{* *} \Delta G_{\text {bind }}=\Delta G_{\mathrm{GB}}-\mathrm{T} \cdot \Delta S$. 


\section{Sample preparation}

Crystals of the inclusion compound of $\mathrm{CHL} / \beta-\mathrm{CD}$ were formed by using the slow cooling crystallization technique. More specific, $10.22 \mathrm{mg}$ ( 0.026 mmoles) of CHL were added in a $2 \mathrm{~mL}$ equimolar aqueous solution of $\beta-\mathrm{CD}$. The mixture was stirred at $70{ }^{\circ} \mathrm{C}$ for $4 \mathrm{~h}$ and gradually cooled to room temperature over a period of seven days.

\section{X-ray crystallography}

A prismatic colorless specimen was used for single crystal $\mathrm{X}$-ray diffraction data collection. The X-ray intensity data were measured at 100(2) $\mathrm{K}$ on a Bruker D8-VENTURE diffractometer, using a $\mathrm{Cu} \mathrm{K} \alpha$ radiation $(\lambda=1.54178 \AA)$ and an Oxford Cryosystems low-temperature device. A total of 3092 frames were collected during the 23.77 hour of total exposure time. Data integration using a narrow-frame algorithm and global-cell refinement were performed with the Bruker SAINT software package [38]. Data were corrected for absorption effects using the Multi-Scan method (SADABS) [38]. The ratio of minimum to maximum apparent transmission was 0.664 .

The structure has been solved by intrinsic phasing method with SHELXT [39] and refined by full-matrix least squares against $F^{2}$ using SHELXL-2014/7 [40] through the SHELXLE GUI [41] giving a final $R_{1}$ index of $\approx 0.10$. Due to the structural complexity of the inclusion compound, soft restraints on bond lengths and angles of the host and guest molecules were applied using the PRODRG2 webserver [42] and along with DFIX, DANG and FLAT commands in SHELXL. H-atoms of $\beta$-CD and cholesterol molecules were placed geometrically for temperature of $100 \mathrm{~K}$ and allowed to ride on the parent atoms by using SHELXL. H-atoms belonging to the disorder water molecules were not placed during refinement. $U_{\text {iso }}(\mathrm{H})$ values were assigned in the range 1.2-1.5 times $U_{\text {eq }}$ of the parent atom. In order to maintain a high $(>6.7)$ data/parameters ratio, anisotropic thermal parameters were imposed only to $\mathrm{O} 2, \mathrm{O} 3$ and $\mathrm{O} 6$ atoms of the host molecules. The graphic programs used to illustrate the crystal structures are Mercury 3.9 [43] and Olex2 [44]. Selected details of structure refinement along with important statistics are given in Table 1. The data can be obtained from The Cambridge Crystallographic Data Centre under the reference number CCDC 1571522.

\section{Molecular dynamics}

MD simulation in explicit solvent environment using the crystallographically determined atomic coordinates of the $\beta-C D$ dimer and the cholesterol guest molecule as the starting system was carried out. The Amber12 program [45] was used for all calculations and data analysis. The CLYCAM_06 force field [46] was applied to the atoms of $\beta-\mathrm{CD}$, whereas GAFF parameters and AM1BCC charges were applied to the guest molecule using ANTECHAMBER [47]. The explicit solvent model TIP3P was used for water forming a periodic, octahedral box of at least $10 \AA$ between the box walls and the complex. The formation of the thick water shell around the structures and the addition of hydrogen atoms in the two systems were performed with xLEaP. The program SANDER was used for both minimization and MD runs. The particle mesh Ewald method with the nonbonded cutoff distance set to $10 \AA$ was used to create periodic boundary conditions. Temperature and pressure controls were performed using a Berendsen-type algorithm with coupling constants of 0.5 ps (equilibration) or 1.0 ps (production). The following protocol was applied: (a) energy minimization for hydrogen atoms, (b) 50 ps equilibration of the water molecules in the canonical ensemble (NVT) using $50 \mathrm{kcal} \mathrm{mol}^{-1} \AA^{-2}$ positional restraints on the complex atoms, (c) unrestrained energy minimization of the system, (d) gradual temperature increase from 5 to $300 \mathrm{~K}$ or $340 \mathrm{~K}$ with $10 \mathrm{kcal} \mathrm{mol}^{-1} \AA^{-2}$ restraints on the complex atoms, (e) gradual release of the restraints at $300 \mathrm{~K}$ or $340 \mathrm{~K}$, (f) density equilibration in the isobaric-isothermal ensemble (NPT) for $250 \mathrm{ps}$ and (g) MD run for $400 \mathrm{ps}$ at $1 \mathrm{~atm}$ and $300 \mathrm{~K}$ or $340 \mathrm{~K}$ in the NPT ensemble. Production runs were carried out at $1 \mathrm{~atm}$ and $300 \mathrm{~K}$ or $340 \mathrm{~K}$ conditions for an additional time of $11 \mathrm{~ns}$ in the NPT ensemble. The trajectories were analyzed in order (a) to calculate the RMSD for both host and guest molecules and (b) monitor the values of some important geometric features during the MD calculations using CPPTRAJ [48]. The figure illustration, the video preparation and some geometric calculations of the MDs were performed using the program VMD 1.9.2 [36]. Moreover, the molecular mechanics/generalized Born surface area (MM/GBSA) method [49], was used for a theoritical estimation of the binding free energy $\Delta G_{\mathrm{GB}}$ of the inclusion complex. The calculations were performed using 10,000 complex frames. Generalized Born ESURF calculated using 'LCPO' surface areas. The $\Delta G_{\mathrm{GB}}$ value includes the terms $\Delta G_{\text {gas }}$ (van der Waals contribution from MM and the electrostatic energy as calculated by the MM force field) and $\Delta G_{\text {solv }}$ (the electrostatic contribution to the solvation free energy calculated by GB model and nonpolar contribution to the solvation free energy calculated using 'LCPO' surface areas) $\Delta G_{\mathrm{GB}}=\Delta G_{\mathrm{gas}}+\Delta G_{\text {solv }}$ as described by Miller et al. [50]. The entropy term $T \cdot \Delta S$ was also calculated from normal mode analysis with constant temperature using the respective module of the Amber 12 suite and added to the $\Delta G_{\mathrm{GB}}$ term according to: $\Delta G_{\text {bind }}=\Delta G_{\mathrm{GB}}-T \cdot \Delta S$.

The entropy term was calculated by taking snapshots every 100 frames for as long as the equilibrated system of the inclusion complex was subjected to MD simulations. However, it should be noted that the estimation of the entropy term is often problematic as the normal mode lacks information of the conformational entropy and alternative methods do not give 
converged results [51]. Thus, this term is usually omitted and the comparison between similar complexes is based on the $\Delta G_{\mathrm{GB}}$ solely.

\section{Supporting Information}

\section{Supporting Information File 1}

Geometrical characteristics of the crystal structure of the $\mathrm{CHL} / \beta-\mathrm{CD}$ inclusion compound. [https://www.beilstein-journals.org/bjoc/content/ supplementary/1860-5397-14-69-S1.pdf]

\section{Acknowledgements}

The research was funded by IKY (State Scholarships Foundation) Fellowships of Excellence for Postgraduate Studies in Greece-Siemens Program.

\section{References}

1. Berger, S.; Raman, G.; Vishwanathan, R.; Jacques, P. F.; Johnson, E. J. Am. J. Clin. Nutr. 2015, 102, 276-294. doi:10.3945/ajcn.114.100305

2. Chang, T.-Y.; Reid, P. C.; Sugii, S.; Ohgami, N.; Cruz, J. C.; Chang, C. C. Y. J. Biol. Chem. 2005, 280, 20917-20920. doi:10.1074/jbc.R400040200

3. Ikonen, E. Nat. Rev. Mol. Cell Biol. 2008, 9, 125-138. doi:10.1038/nrm2336

4. Astray, G.; Gonzalez-Barreiro, C.; Mejuto, J. C.; Rial-Otero, R.; Simal-Gándara, J. Food Hydrocolloids 2009, 23, 1631-1640. doi:10.1016/j.foodhyd.2009.01.001

5. Mahammad, S.; Parmryd, I. Cholesterol Depletion Using Methyl- $\beta$-cyclodextrin. In Methods in Membrane Lipids. Methods in Molecular Biology (Methods and Protocols); Owen, D., Ed.; Humana Press: New York, 2015; Vol. 1232, pp 91-102. doi:10.1007/978-1-4939-1752-5_8

6. Zidovetzki, R.; Levitan, I. Biochim. Biophys. Acta 2007, 1768 , 1311-1324. doi:10.1016/j.bbamem.2007.03.026

7. Zimmer, S.; Grebe, A.; Bakke, S. S.; Bode, N.; Halvorsen, B.; Ulas, T.; Skjelland, M.; De Nardo, D.; Labzin, L. I.; Kerksiek, A.; Hempel, C.; Heneka, M. T.; Hawxhurst, V.; Fitzgerald, M. L.; Trebicka, J.; Björkhem, I.; Gustafsson, J.-A.; Westerterp, M.; Tall, A. R.; Wright, S. D.; Espevik, T.; Schultze, J. L.; Nickenig, G.; Lütjohann, D.; Latz, E. Sci. Transl. Med. 2016, 8, 333ra50. doi:10.1126/scitranslmed.aad 6100

8. Danthi, P.; Chow, M. J. Virol. 2004, 78, 33-41. doi:10.1128/JVI.78.1.33-41.2004

9. Vance, J. E.; Peake, K. B. Curr. Opin. Lipidol. 2011, 22, 204-209. doi:10.1097/MOL.0b013e3283453e69

10. Vance, J. E.; Karten, B. J. Lipid Res. 2014, 55, 1609-1621. doi:10.1194/jl. R047837

11. Liu, B. Clin. Lipidol. 2012, 7, 289-301. doi:10.2217/clp.12.31

12. Davidson, C.; Fishman, Y.; Puskas, I.; Szeman, J.; Sohajda, T.; Sikora, J.; Vanier, M. T.; Szente, L.; Walkley, S. U.; Dobrenis, K. Mol. Genet. Metab. 2016, 117, S38. doi:10.1016/j.ymgme.2015.12.232
13. Motoyama, K.; Nishiyama, R.; Maeda, Y.; Higashi, T.; Ishitsuka, Y.; Kondo, Y.; Irie, T.; Era, T.; Arima, H. Beilstein J. Org. Chem. 2017, 13, 10-18. doi:10.3762/bjoc.13.2

14. Tamura, A.; Yui, N. Sci. Rep. 2014, 4, No. 4356. doi:10.1038/srep04356

15. Brown, A.; Patel, S.; Ward, C.; Lorenz, A.; Ortiz, M.; DuRoss, A.; Wieghardt, F.; Esch, A.; Otten, E. G.; Heiser, L. M.; Korolchuk, V. I.; Sun, C.; Sarkar, S.; Sahay, G. Sci. Rep. 2016, 6, No. 31750. doi:10.1038/srep31750

16. Del Valle, E. M. M. Process Biochem. (Oxford, U. K.) 2004, 39, 1033-1046. doi:10.1016/S0032-9592(03)00258-9

17. Alonso, L.; Cuesta, P.; Fontecha, J.; Juarez, M.; Gilliland, S. E. J. Dairy Sci. 2009, 92, 863-869. doi:10.3168/jds.2008-1452

18. Dias, H. M. A. M.; Berbicz, F.; Pedrochi, F.; Baesso, M. L.; Matioli, G. Food Res. Int. 2010, 43, 1104-1110. doi:10.1016/j.foodres.2010.02.002

19. Kwak, H. S.; Jung, C. S.; Shim, S. Y.; Ahn, J. J. Agric. Food Chem. 2002, 50, 7293-7298. doi:10.1021/jf020568m

20. Jeong, H. J.; Sun, H.; Chogsom, C.; Kwak, H. S. Asian-Australas. J. Anim. Sci. 2014, 27, 537-542. doi:10.5713/ajas.2013.13706

21. Sieber, R. LWT-Food Sci. Technol. 1993, 26, 375-387. doi:10.1006/fstl.1993.1076

22. Cloudy, P.; Létoffé, J. M.; Germain, P.; Bastide, J. P.; Bayol, A.; Blasquez, S.; Rao, R. C.; Gonzalez, B. J. Therm. Anal. 1991, 37, 2497-2506. doi:10.1007/BF01912796

23. Loftsson, T.; Magnúsdóttir, A.; Másson, M.; Sigurjónsdóttir, J. F. J. Pharm. Sci. 2002, 91, 2307-2316. doi:10.1002/jps.10226

24. Nishijo, J.; Moriyama, S.; Shiota, S. Chem. Pharm. Bull. 2003, 51, 1253-1257. doi:10.1248/cpb.51.1253

25. dos Santos, C.; Buera, M. P.; Mazzobre, M. F. J. Sci. Food Agric. 2011, 91, 2551-2557. doi:10.1002/jsfa.4425

26. Ravichandran, R.; Divakar, S. J. Inclusion Phenom. Mol. Recognit. Chem. 1998, 30, 253-270. doi:10.1023/A:1007912809965

27. López, C. A.; de Vries, A. H.; Marrink, S. J. PLoS Comput. Biol. 2011, 7, e1002020. doi:10.1371/journal.pcbi.1002020

28. Yu, Y.; Chipot, C.; Cai, W.; Shao, X. J. Phys. Chem. B 2006, 110, 6372-6378. doi:10.1021/jp056751a

29. López, C. A.; de Vries, A. H.; Marrink, S. J. Sci. Rep. 2013, 3, No. 2071. doi:10.1038/srep02071

30. Mentzafos, D.; Mavridis, I. M.; Le Bas, G.; Tsoucaris, G. Acta Crystallogr., Sect. B 1991, 47, 746-757. doi:10.1107/S010876819100366X

31. Mentzafos, D.; Bethanis, K. In Cyclodextrins: Synthesis, Chemical Applications and Role in Drug Delivery; Ramirez, G. F., Ed.; Nova Science Publishers: Hauppauge, New York, USA, 2015; pp 241-268.

32. Groom, C. R.; Bruno, I. J.; Lightfoot, M. P.; Ward, S. C. Acta Crystallogr., Sect. B 2016, 72, 171-179. doi:10.1107/S2052520616003954

33. Singleton, M. L.; Reibenspies, J. H.; Darensbourg, M. Y. J. Am. Chem. Soc. 2010, 132, 8870-8871. doi:10.1021/ja103774j

34. Wang, E., Chen, G. and Han, C. 'CCDC 724734: Experimental Crystal Structure Determination'. Cambridge Crystallographic Data Centre, 2011, doi:https://dx.doi.org/10.5517/ccsb4jr

35. Yee, E. M. H.; Hook, J. M.; Bhadbhade, M. M.; Vittorio, O.; Kuchel, R. P.; Brandl, M. B.; Tilley, R. D.; Black, D. S.; Kumar, N. Carbohydr. Polym. 2017, 165, 444-454. doi:10.1016/j.carbpol.2017.02.081 
36. Humphrey, W.; Dalke, A.; Schulten, K. J. Mol. Graphics 1996, 14, 33-38. doi:10.1016/0263-7855(96)00018-5

37. Choi, Y.-H.; Yang, C.-H.; Kim, H.-W.; Jung, S. J. Inclusion Phenom. Macrocyclic Chem. 2001, 39, 71-76. doi:10.1023/A:1008196029391

38. APEX 3, SAINT, SADABS Version 2012/11; Bruker-AXS: Madison, Wisconsin, USA, 2012.

39. Sheldrick, G. M. Acta Crystallogr., Sect. A 2015, 71, 3-8. doi:10.1107/S2053273314026370

40. Sheldrick, G. M. Acta Crystallogr., Sect. C 2015, 71, 3-8. doi:10.1107/S2053229614024218

41. Hübschle, C. B.; Sheldrick, G. M.; Dittrich, B. J. Appl. Crystallogr. 2011, 44, 1281-1284. doi:10.1107/S0021889811043202

42. Schüttelkopf, A. W.; van Aalten, D. M. F. Acta Crystallogr., Sect. D: Biol. Crystallogr. 2004, 60, 1355-1363. doi:10.1107/S0907444904011679

43. Macrae, C. F.; Bruno, I. J.; Chisholm, J. A.; Edgington, P. R.; McCabe, P.; Pidcock, E.; Rodriguez-Monge, L.; Taylor, R.; van de Streek, J.; Wood, P. A. J. Appl. Crystallogr. 2008, 41, 466-470. doi:10.1107/S0021889807067908

44. Dolomanov, O. V.; Bourhis, L. J.; Gildea, R. J.; Howard, J. A. K.; Puschmann, H. J. Appl. Crystallogr. 2009, 42, 339-341. doi:10.1107/S0021889808042726

45. Case, D. A.; Cheatham, T. E., III; Darden, T.; Gohlke, H.; Luo, R.; Merz, K. M., Jr.; Onufriev, A.; Simmerling, C.; Wang, B.; Woods, R. J. J. Comput. Chem. 2005, 26, 1668-1688. doi:10.1002/jcc.20290

46. Kirschner, K. N.; Yongye, A. B.; Tschampel, S. M.; González-Outeiriño, J.; Daniels, C. R.; Foley, B. L.; Woods, R. J. J. Comput. Chem. 2008, 29, 622-655. doi:10.1002/jcc.20820

47. Wang, J.; Wang, W.; Kollman, P. A.; Case, D. A. J. Mol. Graphics Modell. 2006, 25, 247-260. doi:10.1016/j.jmgm.2005.12.005

48. Roe, D. R.; Cheatham, T. E., III. J. Chem. Theory Comput. 2013, 9 , 3084-3095. doi:10.1021/ct400341p

49. Wang, J.; Morin, P.; Wang, W.; Kollman, P. A. J. Am. Chem. Soc. 2001, 123, 5221-5230. doi:10.1021/ja003834q

50. Miller, B. R., III; McGee, T. D., Jr.; Swails, J. M.; Homeyer, N.; Gohlke, H.; Roitberg, A. E. J. Chem. Theory Comput. 2012, 8, 3314-3321. doi:10.1021/ct300418h

51. Genheden, S.; Ryde, U. Expert Opin. Drug Discovery 2015, 10 , 449-461. doi:10.1517/17460441.2015.1032936

\section{License and Terms}

This is an Open Access article under the terms of the Creative Commons Attribution License

(http://creativecommons.org/licenses/by/4.0), which permits unrestricted use, distribution, and reproduction in any medium, provided the original work is properly cited.

The license is subject to the Beilstein Journal of Organic Chemistry terms and conditions:

(https://www.beilstein-journals.org/bjoc)

The definitive version of this article is the electronic one which can be found at:

doi:10.3762/bjoc. 14.69 